\title{
A Preliminary Study on the Presence of Salmonella in Lymph Nodes of Sows at Processing Plants in the United States
}

\author{
Roger B. Harvey ${ }^{1, *}$, Keri N. Norman ${ }^{2}$, Robin C. Anderson ${ }^{1}$ and David J. Nisbet ${ }^{1}$ \\ 1 Food and Feed Safety Research Unit, Agricultural Research Service, U.S. Department of Agriculture, \\ College Station, TX 77845-4988, USA; robin.anderson@usda.gov (R.C.A.); david.nisbet@usda.gov (D.J.N.) \\ 2 Department of Veterinary Integrative Biosciences, College of Veterinary Medicine and Biosciences, \\ Texas A\&M University, College Station, TX 77843, USA; KNorman@cvm.tamu.edu \\ * Correspondence: roger.harvey@usda.gov; Tel.: +01-979-260-9259
}

Received: 17 September 2020; Accepted: 16 October 2020; Published: 18 October 2020

\begin{abstract}
Salmonella-contaminated lymph nodes (LN), when included into edible meat products, are a potential source of Salmonella foodborne disease. In this survey, ventral superficial cervical and mandibular LN were tested for the presence of Salmonella from two sow processing plants in the midwestern United States. Results indicate that both LN can be contaminated with Salmonella; mandibular LN have higher prevalence $(p<0.05)$ of Salmonella than cervical LN $(16 \%$ vs. $0.91 \%)$, and the majority ( $>90 \%$ ) of Salmonella isolates are pan-susceptible or resistant to one antimicrobial, while $9.78 \%$ of isolates were multi-drug-resistant (MDR-resistant to three or more classes of antimicrobials). Intervention methods to prevent foodborne disease could include elimination of these $\mathrm{LN}$ from pork products or inclusion of LN only into products that are destined for cooking. Integrated multi-faceted intervention methods need to be developed to reduce Salmonella in the food chain.
\end{abstract}

Keywords: lymph nodes; Salmonella; antimicrobial resistance; prevalence; sows; pork

\section{Introduction}

The Salmonella enterica (hereafter called Salmonella) is one of the top five foodborne pathogens globally and a leading cause of foodborne illness in humans [1]. Salmonella is reported to cause over 1.3 million infections annually in the United States (U.S.) with approximately 1 million traced back to consumption of contaminated food [2]. These health concerns have prompted the beef, pork, and poultry industries to continuously search for mechanisms to reduce the risk of Salmonella contamination of their products. It has been suggested that cattle lymph nodes (LN), when included into beef ground products, could contribute to Salmonella contamination [3]. Indeed, peripheral LN of cattle are in anatomic locations that their inclusion into beef products could be somewhat common. The prevalence of Salmonella-positive subiliac LN in U.S. cattle are reported to be $7.7 \%$ to $62 \%$ [4-7], whereas prevalence of Salmonella in inguinal LN of cattle in Mexico are 54-75\% [6,8]. Of increasing concern is that $8 \%$ to $20 \%$ of Salmonella isolates in those studies were resistant to antimicrobials $[5,7]$.

It is not unreasonable to believe that swine LN, when included in edible pork products, could serve as a source of Salmonella contamination for pork. Salmonella-positive inguinal LN of sows at slaughter are reported to range from $4.8 \%$ to $37 \%$ [9-11] in the U.S., whereas popliteal LN in market hogs is reported to be $12.6 \%$ [12]. A study in Mexican swine abattoirs reported that subiliac LN had a Salmonella prevalence of $10 \%$ to $20 \%$ [13]. There has been limited research on prevalence of Salmonella in swine LN. Salmonella-positive LN represent a risk of contamination to pork products when incorporated into pork products, such as sausage, chorizo, and others $[13,14]$. The objective of this preliminary survey 
was to determine the presence of Salmonella in ventral superficial cervical LN and mandibular LN of sows at processing.

\section{Materials and Methods}

\subsection{Sample Collection}

Two sow processing plants (Plant A and Plant B) in two separate states in the midwestern U.S. were chosen for sampling. Each plant was sampled on two consecutive days each month for twelve months (November 2016-October 2017). Samples consisted of 25 ventral superficial cervical LN on each of days 1 and 2, the first Monday and Tuesday of each month for both Plants A and B (50/month X 12 months $=472$ samples for Plant A and 548 samples for Plant B). In addition, from February-October 2017 (9 months), the same day each month that cervical LN was sampled, we collected 150 mandibular LN from Plant A and 217 LN from Plant B (25/day/month/plant X 9 months = 367). Due to weather and other sampling difficulties, we were unable to collect the full number of samples (both cervical and mandibular) as projected from the original study design.

\subsection{LN Processing, Salmonella Cultivation}

LN samples were processed as previously described for meat samples [15]. Tissues were individually weighed and recorded, surface sterilized by submersion in boiling water for 3-5 s, placed into sterile filtered-stomacher bags (Nasco, Fort Atkinson, WI, USA), macerated by pounding with a rubber mallet until flat, enriched in $80 \mathrm{~mL}$ of tryptic soy broth (Becton Dickinson, Sparks, MD, USA), and homogenized for $30 \mathrm{~s}$ with a laboratory blender (BagMixer 400VW, Interscience Laboratories Inc., Weymouth, MA, USA) at a medium speed (seven paddle strokes per second). The homogenized samples were incubated at $25^{\circ} \mathrm{C}$ for $2 \mathrm{~h}, 42^{\circ} \mathrm{C}$ for $12 \mathrm{~h}$, and then held at $4{ }^{\circ} \mathrm{C}$, for no more that $4-6 \mathrm{~h}$, until further processing. For prevalence analysis, $1 \mathrm{~mL}$ from each enrichment culture was subjected to anti-Salmonella immunomagnetic separation (IMS). Each $1 \mathrm{~mL}$ aliquot received $20 \mu \mathrm{L}$ of anti-Salmonella beads (Invitrogen, Carlsbad, CA, USA) and was incubated with shaking at room temperature for 15 min. The beads were extracted from the enriched samples and washed twice in PBS-Tween 20 (Sigma, St. Louis, MO, USA). The beads were transferred to $3 \mathrm{~mL}$ of Rappaport Vassiliadis soya (RVS; Remel Products, Lenexa, KS, USA) broth and incubated at $42{ }^{\circ} \mathrm{C}$ overnight. Salmonella present in these samples were detected by swabbing the RVS enrichment culture onto brilliant green agar (Becton Dickinson, Sparks, MD, USA) containing sulfadiazine ( $80 \mathrm{mg} / \mathrm{L}$; Sigma, St. Louis, MO, USA). All plates were incubated at $37^{\circ} \mathrm{C}$ for 18 to $20 \mathrm{~h}$. After incubation, up to three presumptive Salmonella colonies were selected and confirmed biochemically with lysine iron and triple sugar iron agars according to the manufacturer's recommendations (BD Difco, Dickinson and Company, Sparks, MD, USA).

\subsection{Antimicrobial Susceptibility Testing}

Susceptibility to 14 antimicrobial agents (cefoxitin (FOX), azithromycin (AZI), chloramphenicol (CHL), tetracycline (TET), ceftriaxone (AXO), amoxicillin/clavulanic acid (AUG2), ciprofloxacin (CIP), gentamicin (GEN), nalidixic acid (NAL), ceftiofur (XNL), sulfisoxazole (FIS), trimethoprim/ sulfamethoxazole (STX), ampicillin (AMP), and streptomycin (STR)) was determined by use of an automated micro-broth dilution method (Sensititre Gram Negative NARMS Plates (CMV3AGNF), TREK Diagnostics Inc., Cleveland, $\mathrm{OH}$ ) according to the manufacturer's recommendations. Isolates were classified as susceptible, intermediate, or resistant using breakpoints established by the Clinical and Laboratory Standards Institute [16]. Isolates that were resistant to three or more classes of antimicrobials, as defined by the National Antimicrobial Resistance Monitoring System (NARMS), were considered multi-drug resistant (MDR). 


\subsection{Statistical Analysis}

Descriptive statistics comparing Salmonella prevalence across LN, plants, month, and day were tabulated in Stata (version 16, Stata Corp, College Station, TX, USA). Logistic regression (Stata version 16) was used to explore associations between Salmonella prevalence within and across LN for plant, month, and day $(p<0.05)$.

\section{Results and Discussion}

Plant A had 28 positive cervical LN/472 tested (5.9\%), whereas Plant B had 5 positive cervical LN/548 tested $(0.9 \%)$ (Figure 1). The Plant A results are similar to that reported for inguinal LN prevalence rates of $37 \%, 8.9 \%$, and $4.8 \%$ in sows and $6.4 \%$ and $13 \%$ in market hogs [9-11], whereas Salmonella prevalence for popliteal LN was $12.55 \%$ in market hogs [12]. Similar to the present study, those studies were in the U.S., whereas a study from abattoirs in Mexico reported $10.2 \%$ and 20\% Salmonella prevalence in subiliac LN [13]. The decreased Salmonella isolation rates (0.73\%) of Plant B in the present study mirror those of $0 \%$ reported for superficial cervical LN [17] and $0.06 \%$ for subiliac LN [18] of market hogs in U.S. plants. Although not peripheral LN, similar Salmonella prevalence results (6.1\%) were reported for mesenteric LN from breeder sows in Spain [19].

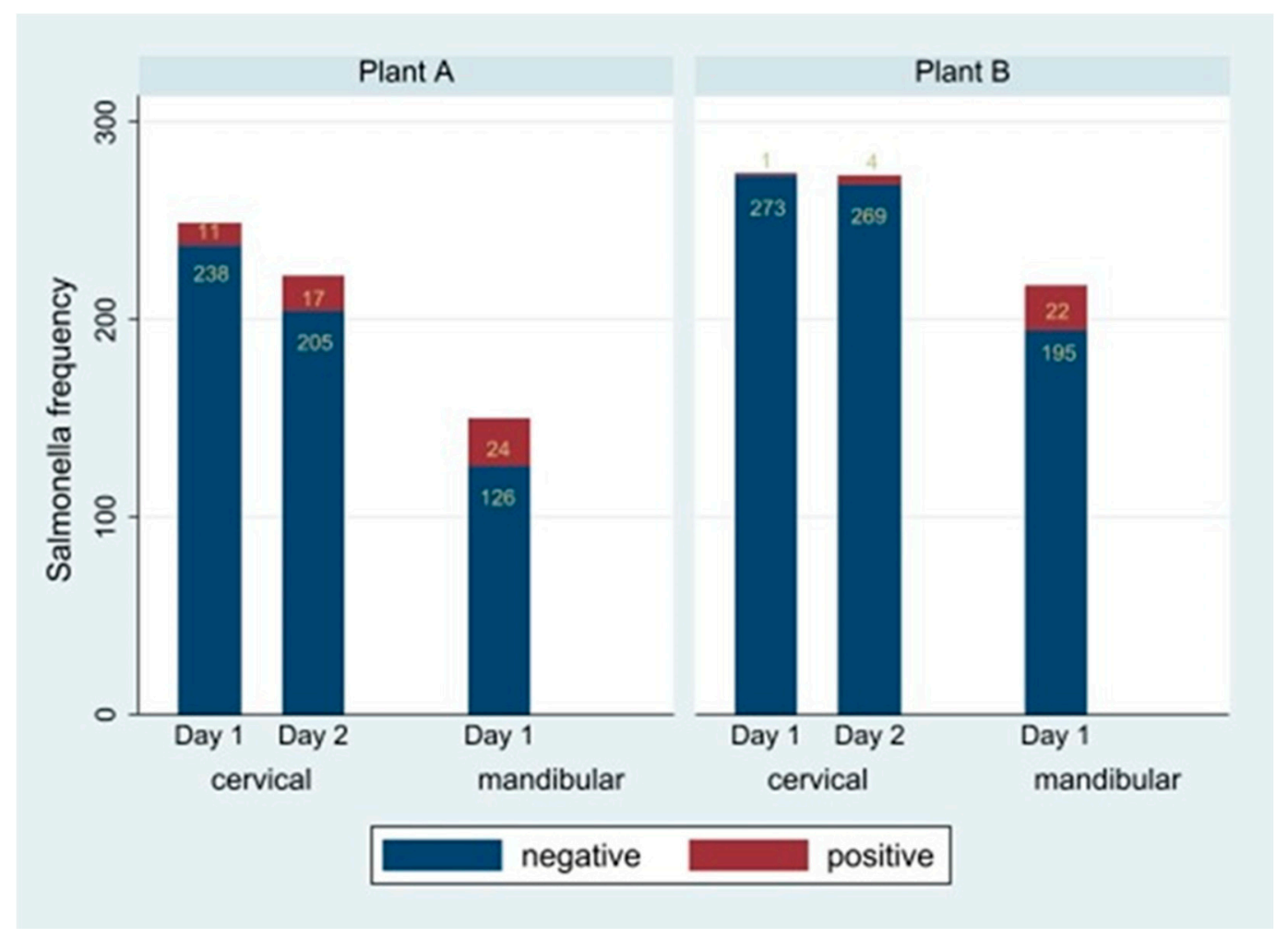

Figure 1. Prevalence of Salmonella in lymph nodes of sows at processing.

For the 9-month testing period for mandibular LN, Plant A had 24 positive/150 tested (16\%) and Plant B had 22 positive/217 tested (10.14\%) (Figure 1). During the collection periods, Plant A had significantly increased Salmonella-positive cervical and mandibular LN samples when compared to Plant B $(p<0.05)$. Additionally, there were seasonal differences in Salmonella-positive samples with August having the highest number of Salmonella isolates when compared to the other months; however, this difference was not statistically significant when analyzing both sample types together $(p=0.22$ (data not shown)) or individually for cervical and mandibular lymph nodes ( $p=0.18$ and $p=0.77$, respectively (data not shown)). For whatever reasons, the second day of samples in Plant A and Plant $B$ had numerically increased Salmonella isolates from cervical lymph nodes when compared to the results 
of the first day; however, this difference was not significant $(p=0.08$ (data not shown)). In both plants, the percentage of Salmonella-positive samples were significantly increased in mandibular LN when compared to cervical LN $(p<0.05)$. This is not a great surprise in that lymphatic tissues that are close to the oral cavity (such as tonsils and parotid LN) tend to have greater Salmonella numbers when compared to peripheral LN sources $[13,20,21]$. Similarly, head trim and cheek meat tissues, anatomically close to the oral cavity, can have a high percentage (65\%) of Salmonella-positive samples [22,23].

Salmonella isolates (64 tested) included 15 different serotypes: Adelaide (1), Agona (8), Alachua (1), Anatum (2), Anatum_var_15 (1), Berta (1), Brandenburg (2), Derby (25), Enteritidis (1), Heidelberg (1), Infantis (15), Johannesburg (1), Minnesota (1), Orion_var_15+34 (1), Typhimurium (1), and Uganda (1).

The majority $(52.5 \%)$ of Salmonella isolates tested were pan-susceptible (no or intermediate resistance) to 14 antimicrobials; $37.8 \%$ were resistant to one class of antimicrobials, and six isolates (9.7\%) were MDR. Two of the six MDR were serotype Brandenburg, one each from serotypes Infantis and Orion_var_15+34, and two isolates from Derby (Table 1). There were four MDR isolates from cervical LN and two from mandibular LN. These results are similar to Salmonella prevalence of $6.1 \%$ in mediastinal LN from sows at slaughter in Spain [19]. In that study, serotypes of isolates were: Typhimurium (43.7\%), Derby (18.7\%), Enteritidis (12.5\%), and Montevideo (12.5\%) with 9/16 of isolates showing multi-resistance to three or more antimicrobial classes (SSuT, ACSSut, and ASSut-Nx-Cfx). Although not LN tissue, the low levels of MDR in the present study contrast with a similarly designed study in which $63 \%$ of Salmonella isolates of cheek meat (anatomically close to mandibular LN) of market hogs were MDR [23].

Table 1. Serotypes and antimicrobial resistance phenotypes of multidrug-resistant Salmonella isolates cultured from lymph nodes (LN) of sows at processing.

\begin{tabular}{ccccccc}
\hline Isolate & LN $^{\mathbf{a}}$ & Plant & Month & Day & Serotype & Resistance $^{\mathbf{b}}$ \\
\hline F8-1 & C & A & Apr & 3 & Derby & STR, FIS, TET \\
I106-1 & MD & A & Jul & 10 & Orion_var_15+34 & AUG2, AMP, FOX, XNL, STR \\
J19-1 & C & A & Aug & 7 & Brandenburg & FIS, TET, STX \\
J18EB1.1 & C & A & Aug & 7 & Brandenburg & FIS, TET, STX \\
J104-2 & MD & A & Aug & 7 & Derby & STR, FIS, TET \\
J51-2 & C & A & Aug & 8 & Infantis & AUG2, AMP, FOX, XNL \\
\hline
\end{tabular}

\section{Conclusions}

On the basis of the results of this survey, it is evident that cervical and mandibular LN can be colonized by Salmonella and inclusion of these LN into pork products may increase the risk those products could be contaminated with Salmonella. Intervention methods to prevent foodborne disease could include elimination of these LN from pork products or inclusion of LN only into products that are destined for cooking. Additional research is needed to further understand the distribution and prevalence of Salmonella in the lymph nodes of commercial sows at slaughter. There is a high priority for the meat industry to utilize a multi-faceted approach to develop effective intervention methods to reduce Salmonella in the food chain.

Author Contributions: R.B.H. provided conceptualization, collection of samples, supervision of laboratory isolation and analysis, coordination with industry partners, and writing, editing, submission, funding, revisions, and re-submission of manuscript; K.N.N. provided conceptualization, methodology, analysis, writing-review and editing; R.C.A. provided visualization, data curation, and writing-original draft preparation; D.J.N. provided funding, supervision, and project administration. "A preliminary study on the presence of Salmonella in lymph nodes of sows at processing plants in the United States". All authors have read and agreed to the published version of the manuscript.

Funding: This research was supported by research funds appropriated by the United States Department of Agriculture. 
Acknowledgments: The authors wish to thank Robert Droleskey and Kathleen Andrews (Food and Feed Safety Research Unit, Agricultural Research Service, U.S. Department of Agriculture, College Station, TX 77845-4988, USA) for excellent technical support that contributed immensely to the successful completion of this manuscript.

Conflicts of Interest: The authors declare no conflict of interest.

\section{References}

1. Havelaar, A.H.; Kirk, M.D.; Torgerson, P.R.; Gibb, H.J.; Hald, T.; Lake, R.J.; Praet, N.; Bellinger, D.C.; De Silva, N.R.; Gargouri, N.; et al. World Health Organization Global Estimates and Regional Comparisons of the Burden of Foodborne Disease in 2010. PLoS Med. 2015, 12, e1001923. [CrossRef] [PubMed]

2. Centers for Disease Control (CDC). Reports of Selected Salmonella Outbreak Investigations. 4 May 2020. Available online: https//www.cdc.gov./Salmonella/outbreaks.html (accessed on 4 August 2020).

3. Arthur, T.M.; Guerini, M.N.; Kalchayanand, N.; Wells, J.E.; Shackelford, S.D.; Wheeler, T.L.; Koohmaraie, M. Prevalence and characterization of Salmonella in bovine lymph nodes potentially destined for use in ground beef. J. Food Prot. 2008, 71, 1685-1688. [CrossRef] [PubMed]

4. Brown, T.R.; Edrington, T.S.; Loneragan, G.H.; Hanson, K.L.; Malin, K.; Ison, J.J.; Nisbet, D.J. Possible differences in Salmonella prevalence in the peripheral lymph nodes of cattle derived from distinct production systems and of different breed types. J. Food Prot. 2015, 78, 2081-2084. [CrossRef] [PubMed]

5. Gragg, S.E.; Loneragan, G.H.; Brashears, M.M.; Arthur, T.M.; Bosilevac, J.M.; Kalchayanand, N.; Wang, R.; Schmidt, J.W.; Brooks, J.C.; Shackelford, S.D.; et al. Cross-sectional study examining Salmonella enterica carriage in subiliac lymph nodes of cull and feedlot cattle at harvest. Foodborne Pathog. Dis. 2013, 10, 368-374. [CrossRef] [PubMed]

6. Nickelson, K.J.; Taylor, T.M.; Griffin, D.B.; Savell, J.W.; Gehring, K.B.; Arnold, A.N. Assessment of Salmonella prevalence in lymph nodes of U.S. and Mexican cattle presented for slaughter in Texas. J. Food Prot. 2019, 82, 310-315. [CrossRef] [PubMed]

7. Webb, H.E.; Brichta-Harhay, D.M.; Brashears, M.M.; Nightingale, K.K.; Arthur, T.M.; Bosilevac, J.M.; Kalchayanand, N.; Schmidt, J.W.; Wang, R.; Granier, S.A.; et al. Salmonella in peripheral lymph nodes of healthy cattle at slaughter. Front. Microbiol. 2017, 8, 2214. [CrossRef] [PubMed]

8. Gragg, S.E.; Loneragan, G.H.; Nightingale, K.K.; Brichta-Harhay, D.M.; Ruiz, H.; Elder, J.R.; Garcia, L.G.; Miller, M.F.; Echeverry, A.; Porras, R.G.R.; et al. Substantial within-animal diversity of Salmonella isolates from lymph nodes, feces, and hides of cattle at slaughter. Appl. Environ. Microbiol. 2013, 79, 4744-4750. [CrossRef] [PubMed]

9. Arnold, A.N.; Gehring, K.B.; Savell, J.W.; Griffin, D.B.; Taylor, M.T. National Survey of Salmonella Prevalence in Lymph Nodes of Sows and Market Hogs-NPB \#16-059 Final Report. 2018. Available online: https://www. pork.org/research/national-survey-salmonella-prevalence-lymph-nodes-sows-market-hogs/ (accessed on 4 August 2020).

10. Campbell, J.A.; Cutter, C.N.; Dudley, E.G. Estimating the National Prevalence of Salmonella spp. in lymph Nodes from Market Hogs and Sows. NPB\#16-120 Final Report. 2018. Available online: https://www.pork.org/ research/estimating-national-prevalence-salmonella-spp-lymph-nodes-market-hogs-sows-2/ (accessed on 4 August 2020).

11. Larsen, S.T.; McKean, J.D.; Hurd, H.S.; Rostagno, M.H.; Griffith, R.W.; Wesley, I.V. Impact of commercial preharvest transportation and holding on the prevalence of Salmonella enterica in cull sows. J. Food Prot. 2003, 66, 1134-1138. [CrossRef] [PubMed]

12. Scaria, J.; Christopher-Hennings, J.; Erickson, A.; Thomas, M.; Mikel, W.B. Estimating the National Prevalence of Salmonella spp. in Lymph Nodes from Market Hogs and Sows. NPB \#16-074 Final Report. 2018. Available online: https://www.pork.org/research/estimating-national-prevalence-salmonella-spp-lymphnodes-market-hogs-sows/ (accessed on 4 August 2020).

13. Chaves, B.D.; Ruiz, H.; Garcia, L.G.; Miller, M.F.; Brashears, M.M. High prevalence of Salmonella in lymph nodes and tonsils of swine presented for slaughter in Mexico. Food Prot. Trends 2017, 37, 25-29.

14. Mann, E.; Dzieciol, M.; Pinior, B.; Neubauer, V.; Metzler-Zebeli, B.U.; Wagner, M.; Schmitz-Esser, S. High diversity of viable bacteria isolates from lymph nodes of slaughtered pigs and its possible impacts for food safety. J. Appl. Microbiol. 2015, 119, 1420-1432. [CrossRef] [PubMed] 
15. Britcha-Harhay, D.M.; Arthur, T.M.; Bosilevac, J.M.; Kalchayanand, N.; Schmidt, J.W.; Wang, R.; Shackelford, S.D.; Loneragan, G.H.; Wheeler, T.L. Microbiological analysis of bovine lymph nodes for the detection of Salmonella enterica. J. Food Prot. 2012, 75, 854-858. [CrossRef] [PubMed]

16. Clinical and Laboratory Standards Institute (CLIS). Performance Standards for Antimicrobial Susceptibility Testing: 24th Informational Suppl (Document M100-S24); CLSI: Wayne, PA, USA, 2014.

17. Bahnson, P.B.; Snyder, C.; Omran, L.M. Salmonella enterica in superficial cervical (prescapular) and ileocecal lymph nodes of slaughtered pigs. J. Food Prot. 2006, 69, 925-927. [CrossRef] [PubMed]

18. Wang, B.; Wesley, I.V.; McKean, J.D.; O'Conner, A.M. Sub-iliac lymph nodes at slaughter lack ability to predict Salmonella enterica prevalence for swine farms. Foodborne Pathog. Dis. 2010, 7, 795-800. [CrossRef] [PubMed]

19. Garrido, V.; Sanchez, S.; San-Roman, B.; Fraile, L.; Migura-Garcia, L.; Grillo, M.-J. Salmonella infection in mesenteric lymph nodes of breeding sows. Foodborne Pathog. Dis. 2020, 17, 411-417. [CrossRef] [PubMed]

20. Vieira-Pinto, M.; Temudo, P.; Martins, C. Occurrence of Salmonella in the ileum, ileocolic lymph nodes, tonsils, mandibular lymph nodes and carcasses of pigs slaughtered for consumption. J. Vet. Med. B 2005, 52, 476-481. [CrossRef] [PubMed]

21. Vieira-Pinto, M.; Tenreiro, R.; Aranha, J.; Martins, C. Relationship between tonsils and mandibular lymph nodes concerning Salmonella sp. infection. Food Res. Int. 2012, 45, 863-866. [CrossRef]

22. Frederick, T.L.; Miller, M.F.; Thompson, L.D.; Ramsey, C.B. Microbial properties of pork cheek meat as affected by acetic acid and temperature. J. Food Sci. 1994, 59, 300-302. [CrossRef]

23. Harvey, R.B.; Norman, K.N.; Loneragan, G.H.; Scott, H.M. Prevalence and Characterization of Salmonella from Head Meat and Trim for Ground at Pork Processing Facilities. NPB Grant \#14-203 Final Report. 2017. Available online: https://www.pork.org/research/prevalence-characterization-salmonella-head-meat-trimground-pork-processing-facilities/ (accessed on 4 August 2020).

Publisher's Note: MDPI stays neutral with regard to jurisdictional claims in published maps and institutional affiliations. 